\title{
Partial liquid ventilation with small volumes of FC 3280 increases survival time in experimental ARDS
}

\author{
U. Kaisers*, M. Max*, J. Walter**, R. Kuhlen*, D. Pappert*, K. Falke*, R. Rossaint*
}

Partial liquid ventilation with small volumes of FC 3280 increases survival time in experimental ARDS. U. Kaisers, M. Max, J. Walter, R. Kuhlen, D. Pappert, K. Falke, R. Rossaint. (C)ERS Journals Ltd 1997.

ABSTRACT: The aim of this study was to determine the prolonged effects of sequential doses of a highly purified perfluorocarbon (FC 3280) on gas exchange and survival time in experimental acute respiratory distress syndrome (ARDS).

The study was prospective, randomized and controlled. Twelve pigs (body weight $30 \pm 5($ mean $\pm \mathrm{sD}) \mathrm{kg}$ ) were surfactant-depleted by repetitive lung lavages, reducing arterial oxygen tension $\left(\mathrm{Pa}_{\mathrm{a}} \mathrm{O}_{2}\right)$ to $6.9 \pm 1.6 \mathrm{kPa}(52 \pm 12 \mathrm{mmHg})$ (mean \pm SD) at an inspired oxygen fraction $\left(F \mathrm{I}, \mathrm{O}_{2}\right)$ of 1.0 . They were then randomized to receive partial liquid ventilation by sequential intratracheal application of $7.5 \mathrm{~mL} \cdot \mathrm{kg}^{-1}$ FC 3280 at 30 min intervals to a cumulative dose of $15 \mathrm{~mL} \cdot \mathrm{kg}^{-1}$ (treatment group), or to receive no further treatment (control group). Haemodynamics and gas exchange were assessed at $\mathbf{3 0} \mathrm{min}$ intervals after instillation, and hourly afterwards in both groups until death.

In the treatment group, $P \mathrm{a}_{1} \mathrm{O}_{2}$ was $8.9 \pm 4.4 \mathrm{kPa}(67 \pm 33 \mathrm{mmHg})$ after $7.5 \mathrm{~mL} \cdot \mathrm{kg}^{-1}$ FC 3280 and $14.1 \pm 9.9 \mathrm{kPa}(106 \pm 74 \mathrm{mmHg})$ after $15 \mathrm{~mL} \cdot \mathrm{kg}^{-1}$ FC 3280 (Ns). In the control group, gas exchange remained unchanged. Haemodynamics were stable in the treatment group and deteriorated in the control group. Peak airway pressures and dynamic compliance were not significantly affected in the treatment group. Mean survival time was $8.2 \pm 4.5 \mathrm{~h}$ in the treatment group and $1.8 \pm 1.4 \mathrm{~h}$ in the control group $(\mathbf{p}<0.05)$. Upon histological examination, both study groups were not significantly different in total lung injury scores.

We conclude that partial liquid ventilation with small volumes of FC 3280 provides improvement in gas exchange and increases survival time in experimental acute respiratory distress syndrome.

Eur Respir J 1997; 10: 1955-1961.

*Klinik für Anästhesiologie und operative Intensivmedizin Virchow-Klinikum, Medizinische Fakultät der Humboldt-Universität zu Berlin, Berlin, Germany. **Institut für Veterinär-Pathologie, Freie Universität, Berlin, Germany.

\section{Correspondence: U. Kaisers}

Klinik für Anästhesiologie und

operative Intensivmedizin

Virchow-Klinikum der

Humboldt Universität zu Berlin

Augustenburger Platz 1

13353 Berlin

Germany

\section{Keywords: Acute lung injury}

acute respiratory distress syndrome

FC 3280

histology

partial liquid ventilation

survival

Received: October 281996

Accepted after revision May 21997

Supported by DFG (RO 2000-1/1).
Mortality from the acute respiratory distress syndrome (ARDS) is typically reported to be greater than 50\% [1]. Since the first clinical description of the syndrome in 1967 [2], mortality rate has not been substantially changed and, thus, the development of new therapeutic strategies is mandatory.

Partial liquid ventilation (PLV), also known as "perfluorocarbon-associated gas exchange", first described by FuHRMAN et al. [3], represents a new technique to support pulmonary gas exchange during mechanical ventilation by delivering gas tidal volumes into a lung with liquid functional residual capacity (FRC). The technique has been studied in healthy animals as well as in experimental lung injury [4-6]. Recently, the first clinical studies using PLV in premature infants as well as in adult ARDS are emerging [7, 8].

The beneficial effects of PLV on gas exchange are explained by the high solubility of oxygen and carbon dioxide in perfluorocarbons and a significant reduction in intrapulmonary shunt. Moreover, perfluorochemicals have high spreading coefficients and low surface tensions, and considerable improvement in lung mechanics has been reported. Volumes of $3-50 \mathrm{~mL} \cdot \mathrm{kg}^{-1}$ have been administered intratracheally, and there is experimental evidence that the efficiency of perfluorocarbons in im- proving oxygenation is dose-dependent, whereas their effects on lung mechanics appear at even small doses, well below the FRC. Up to now, published studies have focused on demonstrating the short-term effectiveness of PLV in improving gas exchange and lung mechanics in experimental as well as in human ARDS [9, 10]. However, there is uncertainty about the appropriate doses of perfluorocarbons and the duration of its action after a single intratracheal instillation. Likewise, the prolonged effectiveness of PLV with small doses of perfluorocarbons in improving survival time in an animal model of acute lung injury has not yet been studied.

We tested the hypothesis that PLV with small doses of perfluorocarbon that do not approximate the FRC might improve gas exchange and survival time in an animal model of ARDS.

Materials and methods

\section{Animal preparation}

Twelve female pigs with a body weight of $30 \pm 5$ (mean \pm SD) $\mathrm{kg}$ were included in the study. The experimental 
protocol was approved by the local government (Sen Ges Soz Berlin IV A 4/5, AZ 0272/94), and the study was performed according to the Helsinki convention for the use and care of animals.

Prior to the experiments, the general status, blood cell count and body temperatures of the animals were examined. Animals were included in the study if no signs of infection were perceptible. Premedication was accomplished with ketamine $\left(10 \mathrm{mg} \cdot \mathrm{kg}^{-1}\right.$ i.m. $)$, midazolam $(0.5$ $\mathrm{mg} \cdot \mathrm{kg}^{-1}$ i.m. $)$ and atropine $\left(0.01 \mathrm{mg} \cdot \mathrm{kg}^{-1}\right.$ i.m. $)$. After peripheral venous access, anaesthesia was induced with intravenous methohexitone $\left(8 \mathrm{mg} \cdot \mathrm{kg}^{-1}\right)$ and fentanyl $(0.01$ $\left.\mathrm{mg} \cdot \mathrm{kg}^{-1}\right)$, and maintained with a continuous infusion of methohexitone $\left(50 \mu \mathrm{g} \cdot \mathrm{kg}^{-1} \cdot \mathrm{min}^{-1}\right)$ and fentanyl $(3 \mu \mathrm{g}$. $\left.\mathrm{kg}^{-1} \cdot \mathrm{min}^{-1}\right)$. All animals received muscle relaxation by an initial bolus of pancuronium bromide $\left(0.15 \mathrm{mg} \cdot \mathrm{kg}^{-1}\right)$, followed by a continuous infusion $\left(2.5 \mu \mathrm{g} \cdot \mathrm{kg}^{-1} \cdot \mathrm{min}^{-1}\right)$ throughout the experiment.

Immediately after induction, the pigs were tracheotomized and intubated with a $7.5-8.0 \mathrm{~mm}$ endotracheal tube (ETT), fitted with a heat moisture exchanger with bacterial filter. Animals were submitted to volume-controlled mechanical ventilation (Servo 900C; Siemens Elema, Lund, Sweden) with a tidal volume of $12 \mathrm{~mL} \cdot \mathrm{kg}^{-1}$, at a frequency of 18 breaths. $\mathrm{min}^{-1}$, with an inspired oxygen fraction $\left(F \mathrm{I}_{2} \mathrm{O}_{2}\right)$ of 1.0 , inspiratory/expiratory ratio of 1:2 and a positive end-expiratory pressure (PEEP) of $5 \mathrm{cmH}_{2} \mathrm{O}$. Prior to lung lavages, the minute ventilation $\left(V^{\prime} \mathrm{E}\right)$ and the respiratory frequency $(f \mathrm{R})$ were adjusted, after obtaining two arterial blood gas analyses separated by $20 \mathrm{~min}$, in order to maintain the animals normocapnic (arterial carbon dioxide tension $\left(\mathrm{Pa}_{\mathrm{a}} \mathrm{CO}_{2}\right) 5.3 \pm 0.8$ $\mathrm{kPa}(40 \pm 6 \mathrm{mmHg}))$. After instrumentation, the abovementioned ventilatory settings were used and kept constant throughout the experiment.

Temperature was maintained within $\pm 0.5^{\circ} \mathrm{C}$ of the prestudy range by using a heating pad. A continuous infusion of balanced electrolyte solution $\left(5 \mathrm{~mL} \cdot \mathrm{kg}^{-1} \cdot \mathrm{h}^{-1}\right)$ was given during the study. Cardiotonic or vasoactive drugs were not administered. Arterial and venous access were performed percutaneously. A pulmonary artery catheter (model 93A-431-7.5 F; Baxter, Irvine, CA, USA) was advanced from the femoral vein using an 8.5 Fr sheath (Baxter).

An $18 \mathrm{G}$ arterial line (Vygon, Ecouen, France) was introduced into the femoral artery. The arterial line and the pulmonary artery catheter were used for blood sampling and collection of haemodynamic data. Cardiac frequency $(f \mathrm{C})$ was determined from the blood pressure curve. Central venous pressure $(P \mathrm{cv})$, mean arterial pressure $(\bar{P}$ a $)$, mean pulmonary artery pressure $\left(\bar{P}_{\text {pa }}\right)$ and pulmonary capillary wedge pressure $\left(P_{\mathrm{cwp}}\right)$ were assessed using a disposable transducer (Baxter) and a monitoring system (Model 66 S; Hewlett-Packard, Böblingen, Germany). Measurements were taken in the supine position with zero reference level at the midaxilla. Vascular pressures were the average taken at end-expiration from three successive respiratory cycles. Cardiac output $\left(\bar{Q}^{\prime}\right)$ was determined with standard thermodilution techniques (Baxter), and expressed as the mean of four measurements using injections of saline $\left(10 \mathrm{~mL}\right.$ at $\left.1-5^{\circ} \mathrm{C}\right)$ arbitrarily performed during different phases of the respiratory cycle.

Arterial and mixed venous blood samples were col- lected anaerobically, placed on ice and analysed within 5 min using standard blood-gas electrodes (ABL 520; Radiometer, Copenhagen, Denmark), and spectrophotometry (OSM 3 Hemoximeter; Radiometer) was performed to obtain haemoglobin concentration and pig arterial oxygen saturation $\left(\mathrm{Sa}_{\mathrm{a}} \mathrm{O}_{2}\right)$ and mixed venous oxygen saturation $\left(S_{\bar{v}}, \mathrm{O}_{2}\right)$.

The following calculations were made. Dynamic respiratory compliance $(C$ dyn $)=$ tidal volume/inflation pressure. Arterial and mixed venous oxygen content $\left(\mathrm{mL} \cdot \mathrm{dL}^{-1}\right)$ were calculated from the following: $\left(\mathrm{Hb} \times 1.34 \times \% \mathrm{O}_{2}\right.$ saturation $)+\left(P \mathrm{a}, \mathrm{O}_{2} \times 0.0031\right)$, where $\mathrm{Hb}$ denotes haemoglobin and $\mathrm{Pa}, \mathrm{O}_{2}$ is arterial oxygen tension. Arterial to venous difference in oxygen content $\left(\mathrm{DA}-\mathrm{a}, \mathrm{O}_{2}\right)$ was calculated from arterial oxygen content $\left(\mathrm{Ca}, \mathrm{O}_{2}\right)$ - mixed venous oxygen content $\left(\mathrm{C} \bar{v}, \mathrm{O}_{2}\right)$. Intrapulmonary shunt $\left(Q^{\prime} \mathrm{s} /\right.$ $Q^{\prime}$ t) was calculated from: $\left(\mathrm{Cc}, \mathrm{O}_{2}-\mathrm{Ca}_{2} \mathrm{O}_{2}\right) /\left(\mathrm{Cc}, \mathrm{O}_{2}-\mathrm{C} \overline{\mathrm{v}}, \mathrm{O}_{2}\right)$, where $\mathrm{Cc}_{\mathrm{c}} \mathrm{O}_{2}$ is the oxygen content of the blood draining from the ideal alveolus ventilated with gas $\left(F \mathrm{I}, \mathrm{O}_{2}=1.0\right)$, as derived from the alveolar gas equation and the oxyhaemoglobin dissociation curve. Arterial oxygen delivery $\left(\mathrm{DO}_{2}\right)\left(\mathrm{mL} \cdot \mathrm{min}^{-1}\right)=$ cardiac output $\times \mathrm{Ca}, \mathrm{O}_{2} \times 10$.

\section{Induction of acute lung injury}

The lavage procedure was performed according to the method of surfactant washout described by LACHMANN et al. [11]. After disconnection from the ventilator, the animal was positioned in the supine, reverse Trendelenburg position at an angle of $60-70^{\circ}$, and the lungs were completely filled with warmed saline $\left(0.15 \mathrm{M}, 37^{\circ} \mathrm{C}, 40\right.$ $\left.\mathrm{mL} \cdot \mathrm{kg}^{-1}\right)$ via the ETT. The animal was then tilted $45^{\circ}$ with the head down, and the lavage fluid was drained by gravitational force until systemic pressure markedly decreased and pulmonary artery pressure increased. After each lavage, the animal was reconnected to the ventilator for at least $20 \mathrm{~min}$ before the next lavage was performed. A minimum of four lavages were performed in supine position, followed by three or four lavages in prone position.

From the third lavage on, arterial blood gas (ABG) values were measured at each lavage. Haemodynamic data and ventilator settings were recorded. Subsequent $\mathrm{ABG}$ and haemodynamic measurements were taken at 15, 30, 45 and 60 min. An increase in $P \mathrm{a}, \mathrm{O}_{2}$ resulted in repetitive lavages until $\mathrm{Pa}_{\mathrm{a}} \mathrm{O}_{2}$ was persistently $<13.3 \mathrm{kPa}$ $(100 \mathrm{mmHg})$, considered to indicate severe respiratory failure.

\section{Experimental protocol}

The perfluorocarbon used in this study (FC 3280; 3M Chemical Products, Neuss, Germany) is a highly purified $\mathrm{C}_{8} \mathrm{~F}_{18}$ molecule. At $25^{\circ} \mathrm{C}$, FC 3280 has a density of $1.75 \mathrm{~g} \cdot \mathrm{cm}^{-3}$, a viscosity of 0.7 centistokes, a vapour pressure of $8.1 \mathrm{kPa}$, a surface tension of $12 \mathrm{mN} \cdot \mathrm{m}^{-1}$, and it dissolves $40 \mathrm{~mL} \mathrm{O}_{2}$ and $192 \mathrm{~mL} \mathrm{CO}_{2} \cdot 100 \mathrm{~mL}^{-1}$.

Following induction of respiratory failure, the animals were randomized to receive either FC 3280 intratrachally (treatment group) or no further treatment (control group). After recording postlavage values of haemodynamics, gas exchange, ventilator settings and airway 
pressure readings, PLV was performed by sequential intratracheal instillation of two aliquots each of 7.5 $\mathrm{mL} \cdot \mathrm{kg}^{-1} \mathrm{FC} 3280$ at $30 \mathrm{~min}$ intervals up to a total volume of $15 \mathrm{~mL} \cdot \mathrm{kg}^{-1}$. FC 3280 was instilled into the trachea with the animal in the supine position during inspiration, using a swivel-connector (Portex, Kent, UK). During the study, animals were ventilated with a conventional gas tidal volume on the perfluorocarbon filled lung (Servo $900 \mathrm{C}$ ), according to the established concept of PLV [3].

Thirty minutes after each step of instillation of FC 3280, haemodynamics, gas exchange and lung mechanics were determined in both groups. Following the instillation interval, measurements were performed hourly until all animals were dead.

\section{Histological examination}

From each lobe (left: cranial, middle, caudal, accessory; right: cranial, caudal), tissue blocks measuring approximately $2 \times 5 \times 1 \mathrm{~cm}$ were fixated in $10 \%$ buffered formalin for a further $24 \mathrm{~h}$, embedded in paraffin, and stained routinely with haematoxylin and eosin (HE), Elastica-van Gieson (EvG), and with the periodic acidSchiff (PAS) reaction. The histological specimens were scored semiquantitatively using a five-point, four-variable scoring system. The variables were based on histological alterations, and included: 1) atelectasis (collapse of alveoli); 2) exudative debris in the airways; 3 ) presence of inflammatory cells (mainly neutrophils); and 4) oedema. A score from 0 to $4(0=$ no change, $1=$ minimal, $2=$ mild, $3=$ moderate and $4=$ severe changes) were assigned for each of the five variables in the five lung specimens of every animal, and the total injury score (sum of all variables) was calculated for every animal. Additionally, the thickness of the alveolar septum was determined. Images of the histological slides were captured by a CCD-camera (WV-CD 130L; Panasonic, Osaka, Japan) mounted on a Leitz Aristoplan microscope (Leitz, Bensheim, Germany) at a magnification of $\times 250$, and analysed on a Macintosh Quadra 660 AV computer (Apple-Macintosh, Cupertino, CA, USA) using the public domain National Institute of Health (NIH) Image program (available on http://rsb.info.nih.gov/ nih-image/).

\section{Statistical analysis}

Results are expressed as mean \pm SD. Treatment effects are presented as the mean values during prelavage and postlavage, and the values during treatment with incremental dosages of perfluorocarbon or during the corresponding time-points in the control group, respectively. Intergroup statistical analysis was performed using Mann-Whitney U-test and Wilcoxon rank sum test. Survival was analysed using log-rank test and KaplanMeier survival curves. Intragroup comparison was made using Friedman's two-way analysis of variance (ANOVA) model, using postlavage data as reference. All tests of significance were two-tailed, and p-values of less than 0.05 were considered significant.

\section{Results}

All animals were comparable with regard to body weight and prestudy conditions. Gas exchange and haemodynamic variables prior to lung lavage were also comparable in both groups (tables 1 and 2).

Table 1. - Haemodynamics of control and treatment groups at baseline, after induction of acute lung injury and subsequent instillation of two $7.5 \mathrm{~mL} \cdot \mathrm{kg}^{-1}$ aliquots of FC 3280 (in the treatment group only) and follow-up observation period

\begin{tabular}{|c|c|c|c|c|c|c|c|c|c|}
\hline $\begin{array}{l}\text { Haemo- } \\
\text { dynamic } \\
\text { variable }\end{array}$ & Baseline & $\begin{array}{l}\text { Lung } \\
\text { injury }\end{array}$ & $\begin{array}{c}\text { FC } 3280 \\
7.5 \mathrm{~mL} \cdot \mathrm{kg}^{-1}\end{array}$ & $\begin{array}{l}\text { FC } 3280 \\
15 \mathrm{~mL} \cdot \mathrm{kg}^{-1}\end{array}$ & $+2 \mathrm{~h}$ & $+3 \mathrm{~h}$ & $+4 \mathrm{~h}$ & $+5 \mathrm{~h}$ & $+6 \mathrm{~h}$ \\
\hline \multicolumn{10}{|c|}{$f \mathrm{C}$ beats $\cdot \mathrm{min}^{-1}$} \\
\hline $\mathrm{C}$ & $115 \pm 19$ & $150 \pm 20$ & $151 \pm 36$ & $148 \pm 70$ & $147(n=2)$ & & & & \\
\hline $\mathrm{FC}$ & $128 \pm 19$ & $139 \pm 13$ & $141 \pm 18$ & $149 \pm 25$ & $153 \pm 29$ & $154 \pm 33$ & $141 \pm 29$ & $129 \pm 21$ & $113 \pm 19$ \\
\hline \multicolumn{10}{|c|}{$\bar{P}_{\mathrm{a}} \mathrm{mmHg}$} \\
\hline $\mathrm{C}$ & $97 \pm 14$ & $81 \pm 22$ & $65 \pm 11$ & $66 \pm 8$ & $63(n=2)$ & & & & \\
\hline $\mathrm{FC}$ & $104 \pm 24$ & $93 \pm 10$ & $95 \pm 21$ & $98 \pm 23$ & $91 \pm 27$ & $86 \pm 28$ & $83 \pm 20$ & $79 \pm 29$ & $85 \pm 39$ \\
\hline \multicolumn{10}{|c|}{$\bar{P}_{\text {pa }} \mathrm{mmHg}$} \\
\hline $\mathrm{C}$ & $24 \pm 7$ & $41 \pm 11$ & $36 \pm 6$ & $39 \pm 9$ & $37(n=2)$ & & & & \\
\hline $\mathrm{FC}$ & $21 \pm 5$ & $35 \pm 5$ & $36 \pm 4$ & $37 \pm 3$ & $38 \pm 4$ & $34 \pm 10$ & $34 \pm 12$ & $36 \pm 9$ & $36 \pm 10$ \\
\hline \multicolumn{10}{|c|}{$P_{\mathrm{cv}} \mathrm{mmHg}$} \\
\hline $\mathrm{C}$ & $11 \pm 5$ & $13 \pm 4$ & $10 \pm 2$ & $12 \pm 4$ & $14(n=2)$ & & & & \\
\hline \multirow{2}{*}{\multicolumn{10}{|c|}{$P_{\text {cwp }} \mathrm{mmHg}$}} \\
\hline & & & & & & & & & \\
\hline $\mathrm{C}$ & $10 \pm 6$ & $13 \pm 3$ & $11 \pm 2$ & $9 \pm 2$ & $8(n=2)$ & & & & \\
\hline FC & $9 \pm 5$ & $13 \pm 4$ & $14 \pm 5$ & $15 \pm 5$ & $14 \pm 5$ & $14 \pm 4$ & $14 \pm 5$ & $13 \pm 5$ & $12 \pm 2$ \\
\hline \multicolumn{10}{|c|}{$\bar{Q}^{\prime} \quad \mathrm{L} \cdot \mathrm{min}^{-1}$} \\
\hline $\mathrm{C}$ & $4.1 \pm 1.5$ & $4.5 \pm 1.8$ & $4.3 \pm 2.5$ & $2.7 \pm 0.6$ & $2.4(n=2)$ & & & & \\
\hline $\mathrm{FC}$ & $5.1 \pm 0.9$ & $6.5 \pm 1.4 *$ & $6.6 \pm 1.5$ & $6.5 \pm 1.7 *$ & $6.1 \pm 1.1$ & $6.2 \pm 1.6$ & $5.7 \pm 2.8$ & $5.3 \pm 1.4$ & $5.3 \pm 0.7$ \\
\hline \multicolumn{10}{|c|}{$\mathrm{SVR}$ dyn $\cdot \mathrm{cm} \cdot \mathrm{s}^{-5}$} \\
\hline $\mathrm{C}$ & $1780 \pm 764$ & $1525 \pm 686$ & $1447 \pm 824$ & $1912 \pm 494$ & $1947(n=2)$ & & & & \\
\hline $\mathrm{FC}$ & $1461 \pm 446$ & $1052 \pm 245$ & $1091 \pm 441$ & $1144 \pm 477$ & $1113 \pm 520$ & $1011 \pm 518$ & $1108 \pm 471$ & $1101 \pm 739$ & $1089 \pm 601$ \\
\hline
\end{tabular}

Data are presented as mean \pm SD. C: control; FC: FC 3280; $f$ C: cardiac frequency; $\bar{P}$ a: mean arterial pressure; $\bar{P}$ pa: mean pulmonary artery pressure; $P_{\mathrm{cv}}$ : central venous pressure; $P_{\mathrm{cwp}}$ : pulmonary capillary wedge pressure; $\bar{Q}^{\prime}$ : cardiac output; SVR: systemic vascular resistance. $*$ : $\mathrm{p}<0.05$, statistically different compared to control. 
Table 2. - Gas exchange and respiratory mechanics of control and treatment groups at baseline, after induction of acute lung injury and subsequent instillation of two $7.5 \mathrm{~mL} \cdot \mathrm{kg}^{-1}$ aliquots of FC 3280 (in the treatment group only) and follow-up observation period

\begin{tabular}{|c|c|c|c|c|c|c|c|c|c|}
\hline Group & Baseline & $\begin{array}{l}\text { Lung } \\
\text { injury }\end{array}$ & $7.5 \mathrm{~mL} \cdot \mathrm{kg}^{-1}$ & $15 \mathrm{~mL} \cdot \mathrm{kg}^{-1}$ & $+2 \mathrm{~h}$ & $+3 \mathrm{~h}$ & $+4 \mathrm{~h}$ & $+5 \mathrm{~h}$ & $+6 \mathrm{~h}$ \\
\hline \multicolumn{10}{|c|}{$\mathrm{Hb} g \cdot \mathrm{dL}^{-1}$} \\
\hline $\mathrm{C}$ & $10 \pm 1$ & $10 \pm 1$ & $10 \pm 1$ & $10 \pm 1$ & $10(n=2)$ & & & & \\
\hline FC & $10 \pm 1$ & $10 \pm 1$ & $10 \pm 1$ & $10 \pm 1$ & $10 \pm 1$ & $10 \pm 1$ & $10 \pm 1$ & $10 \pm 1$ & $10 \pm 1$ \\
\hline \multicolumn{10}{|l|}{$\mathrm{pH}$} \\
\hline $\mathrm{C}$ & $7.41 \pm 008$ & $7.18 \pm 0.11$ & $7.19 \pm 0.18$ & $7.17 \pm 0.13$ & $7.17(\mathrm{n}=2)$ & & & & \\
\hline FC & $7.43 \pm 0.04$ & $7.27 \pm 0.12$ & $7.27 \pm 0.11$ & $7.25 \pm 0.15$ & $7.27 \pm 0.14$ & $7.22 \pm 0.11$ & $7.19 \pm 0.13$ & $7.20 \pm 0.12$ & $7.21 \pm 0.1$ \\
\hline \multicolumn{10}{|c|}{$\mathrm{HbO}_{2} \%$} \\
\hline $\mathrm{C}^{2}$ & $98 \pm 1$ & $66 \pm 15$ & $77 \pm 20$ & $65 \pm 15$ & $65(n=2)$ & & & & \\
\hline FC & $99 \pm 1$ & $65 \pm 33$ & $74 \pm 24$ & $81 \pm 18$ & $86 \pm 12 * \S$ & $84 \pm 20$ & $85 \pm 26$ & $97 \pm 4$ & $91 \pm 8$ \\
\hline \multicolumn{10}{|c|}{$\mathrm{Pa}_{\mathrm{a}, \mathrm{O}_{2}} \mathrm{mmHg}$} \\
\hline C & $456 \pm 48$ & $51 \pm 8$ & $49 \pm 3$ & $56 \pm 17$ & $52(n=2)$ & & & & \\
\hline FC & $510 \pm 63$ & $54 \pm 16$ & $67 \pm 33$ & $106 \pm 74$ & $121 \pm 94$ & $146 \pm 99$ & $133 \pm 125$ & $170 \pm 165$ & $183 \pm 174$ \\
\hline \multicolumn{10}{|c|}{$\mathrm{Pa}_{\mathrm{a}, \mathrm{CO}_{2}} \mathrm{mmHg}$} \\
\hline $\mathrm{C}$ & $39 \pm 4$ & $66 \pm 28$ & $62 \pm 24$ & $63 \pm 6$ & $61(n=2)$ & & & & \\
\hline FC & $43 \pm 4$ & $61 \pm 14$ & $61 \pm 15$ & $64 \pm 18$ & $65 \pm 20$ & $65 \pm 27$ & $62 \pm 27$ & $60 \pm 39$ & $60 \pm 40$ \\
\hline \multicolumn{10}{|c|}{ PIP $\mathrm{cmH}_{2} \mathrm{O}$} \\
\hline $\mathrm{C}$ & $22 \pm 5$ & $38 \pm 4$ & $39 \pm 4$ & $38 \pm 3$ & $38(n=2)$ & & & & \\
\hline $\mathrm{FC}$ & $23 \pm 4$ & $35 \pm 4$ & $35 \pm 4$ & $35 \pm 4$ & $38 \pm 6$ & $40 \pm 6^{\S}$ & $38 \pm 5^{\S}$ & $36 \pm 3$ & $36 \pm 6$ \\
\hline \multicolumn{10}{|c|}{$C$ dyn $\mathrm{mL} \cdot \mathrm{cmH}_{2} \mathrm{O}^{-1}$} \\
\hline $\mathrm{C}$ & $22 \pm 5$ & $11 \pm 2$ & $10 \pm 1$ & $9 \pm 1$ & $10(n=2)$ & & & & \\
\hline FC & $23 \pm 9$ & $11 \pm 2$ & $12 \pm 4$ & $12 \pm 2$ & $12 \pm 3$ & $11 \pm 2$ & $12 \pm 2$ & $12 \pm 1$ & $11 \pm 1$ \\
\hline \multicolumn{10}{|c|}{$Q^{\prime} \mathrm{s} / Q^{\prime} \mathrm{t} \%$} \\
\hline C & $16 \pm 6$ & $66 \pm 19$ & $69 \pm 20$ & $64 \pm 24$ & $69(n=2)$ & & & & \\
\hline $\mathrm{FC}$ & $14 \pm 5$ & $64 \pm 26$ & $57 \pm 25$ & $52 \pm 23$ & $44 \pm 25$ & $42 \pm 30$ & $44 \pm 36$ & $29 \pm 28$ & $26 \pm 23$ \\
\hline \multicolumn{10}{|c|}{$\mathrm{DO}_{2} \mathrm{~mL} \cdot \mathrm{min}^{-1}$} \\
\hline $\mathrm{C}$ & $621 \pm 268$ & $402 \pm 131$ & $427 \pm 178$ & $253 \pm 106$ & $199(n=2)$ & & & & \\
\hline $\mathrm{FC}$ & $830 \pm 132$ & $631 \pm 131 *$ & $684 \pm 182$ & $734 \pm 212 *$ & $706 \pm 159$ & $622 \pm 178$ & $840 \pm 119$ & $722 \pm 60$ & $742 \pm 66$ \\
\hline
\end{tabular}

Data are presented as mean \pm SD. C: control; FC: $\mathrm{FC} 3280 ; \mathrm{HbO}_{2}$ : oxyhaemoglobin saturation; $P_{\mathrm{a}, \mathrm{O}_{2}}:$ arterial oxygen tension; $P$ a, $\mathrm{CO}_{2}$ : arterial carbon dioxide tension; PIP: peak inspiratory pressure; $C$ dyn: dynamic compliance; $Q^{\prime} \mathrm{s} / Q^{\prime} \mathrm{t}$ : intrapulmonary shunt; $\mathrm{DO}_{2}$ : systemic oxygen delivery. $*: \mathrm{p}<0.05$, statistically different compared to control. $\$: \mathrm{p}<0.05$, statistically different by intragroup comparison of analysis of variance (ANOVA), using lung injury (postlavage) data as reference. $(1 \mathrm{mmHg}=0.133 \mathrm{kPa})$.

Induction of lung injury caused a marked decrease in $P \mathrm{a}, \mathrm{O}_{2}$ and $C$ dyn in both groups (table 2). Peak airway pressure, $\bar{P}$ pa, intrapulmonary shunt and $P \mathrm{a}, \mathrm{CO}_{2}$ were increased after surfactant washout in both groups. Cardiac output was significantly higher in the treatment group compared to the control group following the lavage manoeuvre $(p<0.05)$. Consequently, the corresponding values of oxygen delivery were higher in the FC 3280 group compared to the controls.

Figure 1 represents individual values of $\mathrm{Pa}_{\mathrm{a}} \mathrm{O}_{2}$ in both groups during a period of $8 \mathrm{~h}$ following lung injury. PLV with $7.5 \mathrm{~mL} \cdot \mathrm{kg}^{-1}$ FC 3280 induced a slight, but not significant, increase in $\mathrm{Pa}, \mathrm{O}_{2}$ in the treatment group compared to postlavage values. The difference in $\mathrm{Pa}, \mathrm{O}_{2}$ compared to the control group was not significant. The second dose of FC 3280 induced an increase in $\mathrm{Pa}_{\mathrm{a}} \mathrm{O}_{2}$ in three of the animals in the treatment group, whereas the others did not respond.

$\mathrm{DO}_{2}$ was significantly increased in the treatment group after the second instillation of FC 3280 compared to the control group $(\mathrm{p}<0.05)$ (table 2$)$. Peak inspiratory pressure was significantly increased in the treatment group, compared to postlavage values $3 \mathrm{~h}$ following lung injury $(\mathrm{p}<0.05$ by ANOVA). Neither $C$ dyn nor $Q$ 's $/ Q$ 't were significantly affected in either group.

In the subsequent observation period, gas exchange and haemodynamic variables were largely stable in two of the three initially responsive animals from the treat-

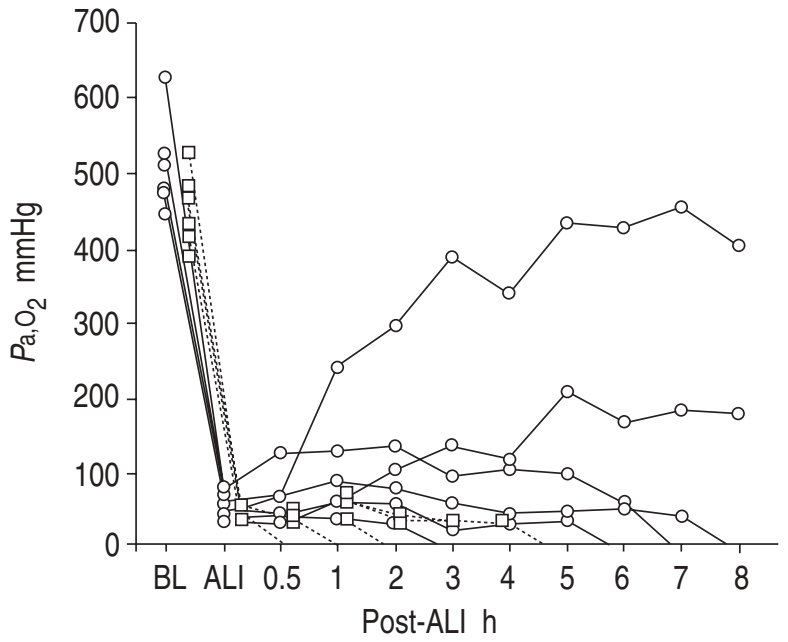

Fig. 1. - Individual values of $P_{\mathrm{a}, \mathrm{O}_{2}}$ during baseline (BL), after induction of acute lung injury (ALI) and after subsequent instillation of two $7.5 \mathrm{~mL} \cdot \mathrm{kg}^{-1}$ aliquots of FC $3280(0.5$ and $1 \mathrm{~h}$, in the treatment group only; and measurements at equivalent time-points in the control group) and during a following observation period of $8 \mathrm{~h}$..-.-.control group; - —— : treatment group $(+\mathrm{FC} 3280) .(1 \mathrm{mmHg}=0.133$ $\mathrm{kPa})$.

ment group following $15 \mathrm{~mL} \cdot \mathrm{kg}^{-1} \mathrm{FC} 3280$; whereas, in the nonresponders and in the control group, gas exchange deteriorated within the first few hours of the 


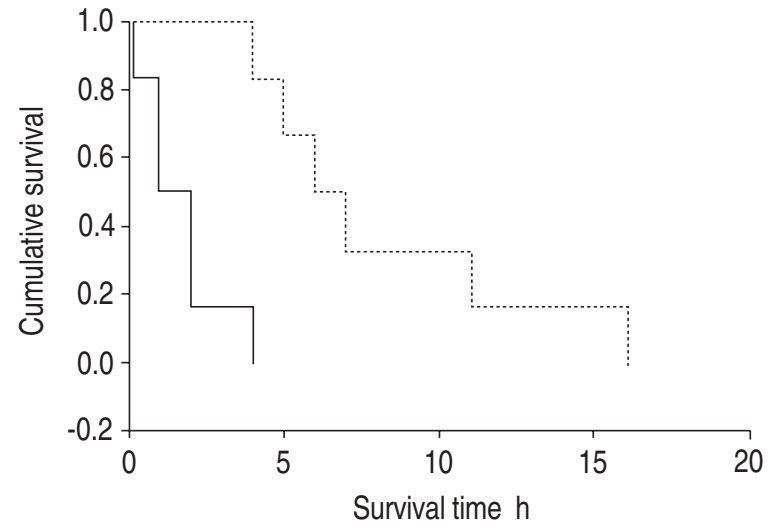

Fig. 2. - Kaplan-Meier survival curve of treatment (FC 3280, n=6) and control animals $(n=6)$ during the experiment. The difference between groups is statistically significant using log-rank test $(\mathrm{p}<0.05)$. ------: treatment group (+FC 3280); —— control group.

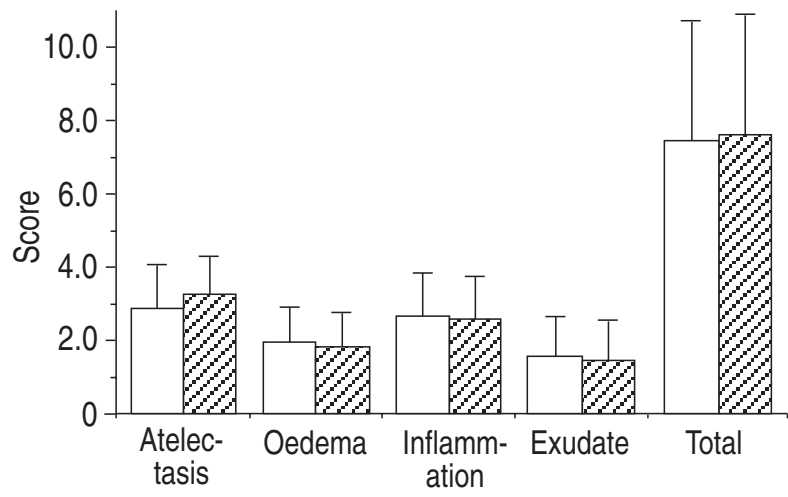

Fig. 5. - Results of semiquantitative assessment of histopathological changes of lung histology in FC 3280 ( $\square$ ) and control animals $(\square)$. The mean scores $( \pm S D)$ are given according to the following scoring system: $0=$ no change; $1=$ minimal change; $2=$ mild change; $3=$ moderate change; $4=$ severe change.

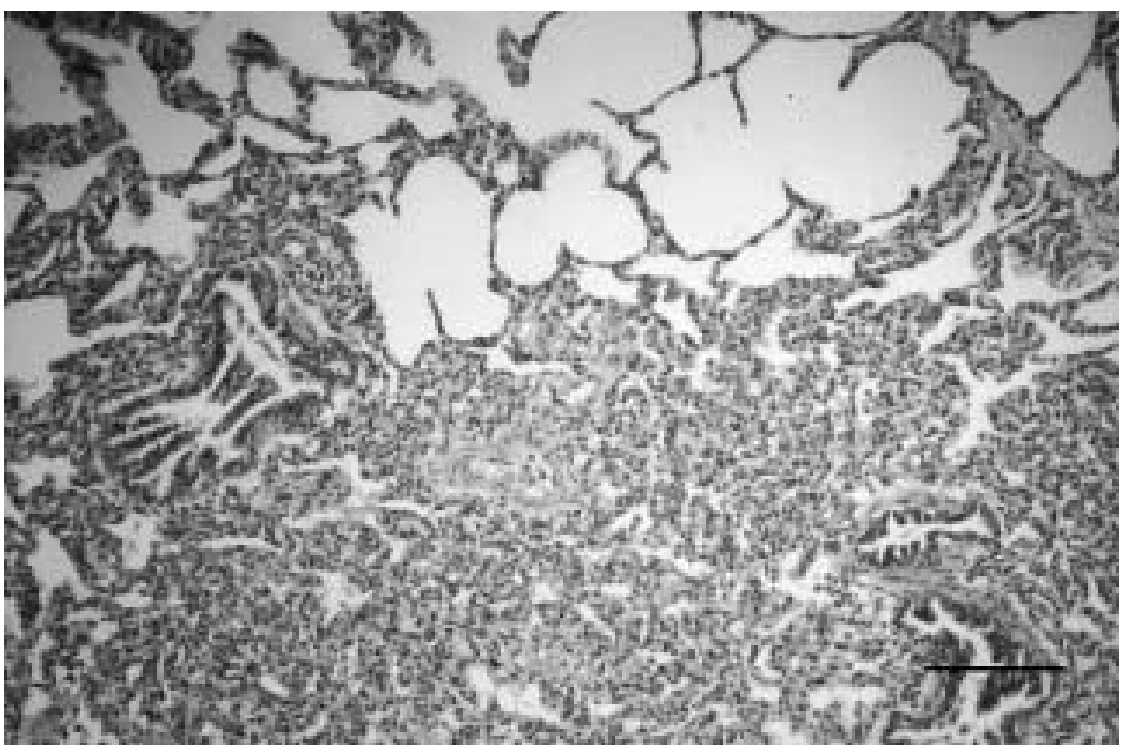

Fig. 3. - Histological specimen (control group). About $50 \%$ of the lung tissue is atelectatic. Alveolar septa are thickened by an interstitial oedema and by granulocytes. (Haematoxylin and eosin stain; internal scale bar $=100 \mu \mathrm{m}$ ).

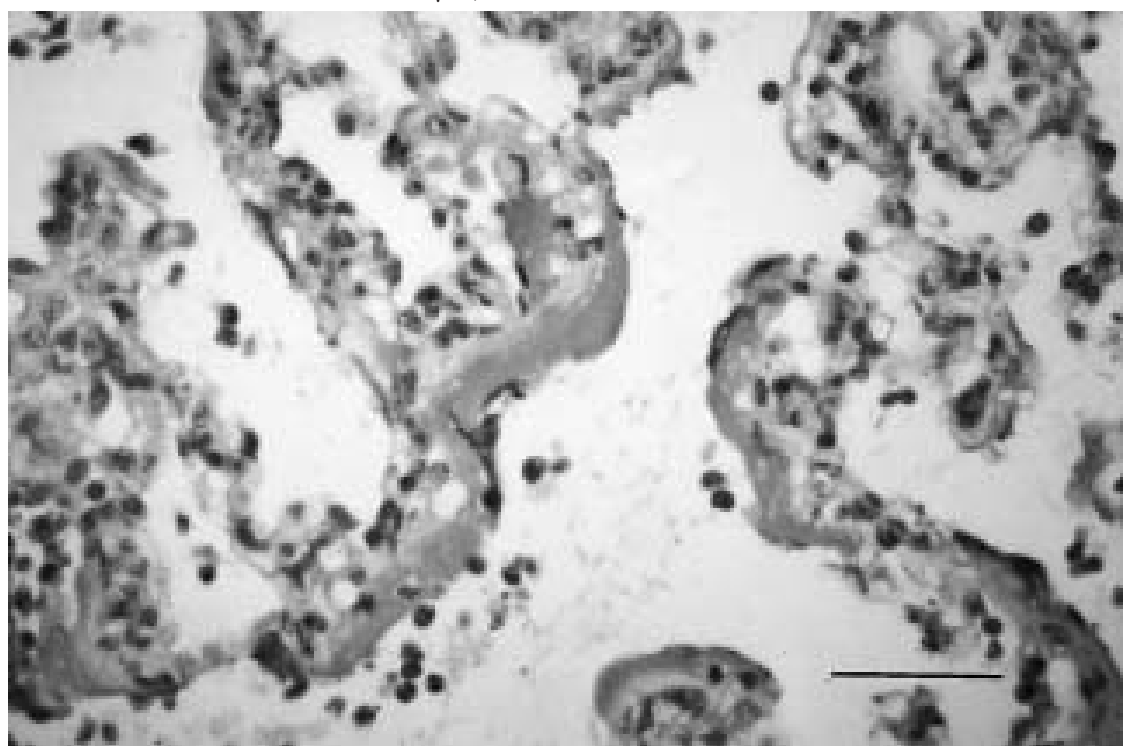

Fig. 4. - Histological specimen (FC 3280 group) of right cranial lung lobe. The alveolar septa are thickened, with formation of a hyaline membrane. (Periodic acid-Schiff reaction; internal scale bar $=50 \mu \mathrm{m})$. experiment causing hypoxaemia, hypercapnia, acidosis and death (tables 1 and 2 and fig. 2).

Four hours after induction of lung injury, one out of six animals was alive in the control group, and five out of six animals in the treatment group. Mean survival time was $1.8 \pm$ $1.4(0.1-4) \mathrm{h}$ for the control group, and $8.2 \pm 4.5(4-16) \mathrm{h}$ for the FC 3280 group ( $\mathrm{p}<0.05$ by log-rank-test) (fig. 2).

In both groups, gross autopsy demonstrated bulky lesions, characterized by severe consolidation, oedema formation (interstitial and pulmonary), atelectasis, and eventually pulmonary haemorrhage, especially in the posterior regions of the lungs, alternating with well-inflated or even hyperinflated, emphysematous regions. In the treatment group, a few small menisci of perfluorocarbon were recognizable in larger airways of dependent lung regions. Right heart dilatation was demonstrated in five of the control group and four of the treatment group. Pneumothoraces were confirmed in one of the control group and two of the PLV group subsequent to ruptured bullous emphysema. Upon histological examination, atelectasis alternated with hyperinflated or emphysematous regions in all animals (fig. 3). The alveolar septa were broadened by an oedema and by a cellular infiltrate (fig. 4). Animals of the treatment group tended to have less atelectasis and slightly thinner alveolar septa (mean $5.14 \pm 1.37 \mu \mathrm{m}$ ) when compared to controls (mean 5.45 \pm 2.11 $\mu \mathrm{m})$ (Ns). The two study groups did not differ significantly in exudative, inflammatory, oedema or total injury scores (fig. 5). 


\section{Discussion}

Since the first description of PLV [3], various studies demonstrating short-term effectiveness of perfluorocarbons on gas exchange and respiratory mechanics have been published [4-6, 9]. The present study indicates that PLV, even with small volumes of FC 3280 that do not approximate the FRC, significantly improves survival time in an animal model of severe ARDS.

PLV with perfluorochemicals, using a hybrid of liquid and gas techniques, in which a conventional gas tidal volume is superimposed on perfluorocarbon-filled lungs, has been investigated extensively in adult and premature animals with and without experimental lung injury.

The perfluorocarbon recently under investigation for PLV is perflubron (perfluoro-octyl bromide, $\mathrm{C}_{8} \mathrm{~F}_{17} \mathrm{Br}$ ). However, the availability of perflubron for experimental as well as for clinical purposes is restricted, and, thus, different perfluorocarbons are under scrutiny for PLV in our institutions. In this study, FC 3280, a highly purified $\mathrm{C}_{8} \mathrm{~F}_{18}$ perfluorochemical, was used. The comparability of the two substances in terms of efficiency in improving gas exchange and respiratory mechanics in experimental ARDS has been demonstrated previously [12].

To evaluate survival time following small volume PLV, a surfactant washout model was used [11], that has been persuasively demonstrated to resemble the pathophysiological and morphological features of severe ARDS.

There are, however, only limited data available reporting FRC volume ranges in surfactant depleted pigs. Using a sulphur hexafluoride $\left(\mathrm{SF}_{6}\right)$ tracer gas technique, WEGENIUS et al. [13] determined the FRC in anaesthetized, lavaged pigs during mechanical ventilation with a PEEP of $6 \mathrm{cmH}_{2} \mathrm{O}$ to be approximately $27 \mathrm{~mL} \cdot \mathrm{kg}^{-1}$. In the present study, volumes of perfluorocarbons (15 $\mathrm{mL} \cdot \mathrm{kg}^{-1}$ ) applied presumably did not approximate FRC volumes of surfactant-depleted pigs. The repetitive lung lavages induced a severe deterioration in gas exchange and respiratory mechanics, while intrapulmonary shunt and right ventricular afterload were significantly increased in both study groups. Animals in the treatment group tended to have higher $\mathrm{Pa}_{\mathrm{a}} \mathrm{O}_{2}$ and $\mathrm{pH}$, and a more stable haemodynamic function in the course of the experiment. Mean short-term survival was increased more than fourfold in the PLV group compared to the controls, presumably owing to a better preserved oxygen delivery during the protocol. Nevertheless, histological findings in both groups confirmed the severity of the lung damage induced, and although atelectasis of lung regions and thickness of the alveolar septa tended to be less severe in the PLV group, the total lung injury score was not different from the controls.

However, postlavage values of cardiac output and, consequently, $\mathrm{DO}_{2}$, were significantly higher in the treatment group compared to the controls, possibly due to interindividual differences in cardiocirculatory response to hypoxia and hypercapnia. In the remainder, hypoxia prevailed and haemodynamic function deteriorated during the experiment, whereas in the treatment group, $\mathrm{DO}_{2}$ was well maintained and reached prelavage values $4 \mathrm{~h}$ after FC 3280. The postlavage difference in $\mathrm{DO}_{2}$ and, thus, in tissue oxygenation prior to the instillation of FC 3280 could also have accounted for an increase in survival time in the perfluorocarbon group.

Values of $\mathrm{Pa}, \mathrm{O}_{2}$ varied considerably within the PLV group, and, notably, three of the six animals in the treatment group demonstrated a remarkable increase in $\mathrm{Pa}, \mathrm{O}_{2}$ whereas three animals did not. Among the animals responding well, two had increased values of $P \mathrm{a}, \mathrm{O}_{2} 8 \mathrm{~h}$ postlavage. A dose dependency in improvement of gas exchange during PLV is well established, and volumes of perfluorocarbons as small as $3 \mathrm{~mL} \cdot \mathrm{kg}^{-1}$ has been shown to be effective in small animals weighing $<10 \mathrm{~kg}$. However, when submitted to PLV, larger animals with ARDS might present an inhomogenous distribution of ventilation due to a larger gravity-induced pressure gradient of dependent and nondependent lung regions. Thus, dependent lung regions may have a low ventilation/perfusion ratio and remain hypoxic. Due to the vapour pressure of FC 3280, which is almost 10 times higher than that of perflubron, the rate of evaporation of the substance from the alveolar liquid-gas interface is probably increased. In a previous study on surfactant-depleted rabbits [12], additional doses of $4.0 \pm 3.1 \mathrm{~mL} \cdot \mathrm{kg}^{-1} \cdot \mathrm{h}^{-1}$ of FC 3280 were required to compensate for evaporational losses, in order to keep gas exchange stable.

In contrast to studies reporting an effective $\mathrm{CO}_{2}$ elimination during PLV with perflubron [4, 5, 9], we could not demonstrate a significant decrease in $\mathrm{Pa}_{\mathrm{a}} \mathrm{CO}_{2}$ with small volumes of FC 3280. Unlike most published studies, we did not adapt ventilatory settings to an increase in $\mathrm{Pa}, \mathrm{CO}_{2}$ following lung injury $[4,14]$, thereby matching the clinical situation of hypercapnia in human ARDS. In rabbit models of surfactant depletion, a significant decrease in $\mathrm{Pa}, \mathrm{CO}_{2}$ was accomplished at volumes of perfluorocarbons well below [9] and almost approximating FRC [12].

Despite a well-maintained body temperature, and although there were no significant changes in cardiovascular parameters and $\mathrm{DO}_{2}$ in the treatment group, a mean $\mathrm{pH}$ below 7.30 was measured during the protocol. Metabolic acidosis during PLV has previously been reported in normocapnic animals, and has been attributed to changes in organ blood flow $[9,15]$.

The clinically relevant complication that could be related to PLV described in various studies was pneumothorax $[7,16,17]$. In the present series, the rate of occurrence of pneumothorax was two out of six animals treated with FC 3280 compared to one out of six in the control group. Due to the small number of animals studied, it is difficult to determine whether there is a true difference in frequency. In established ARDS, inhomogeneous distribution of a liquid that reduces surface tension results in nonuniform alveolar distension and remaining areas of high surface tension and end-expiratory collapse [18]. Since perfluorocarbons have remarkably low, but constant surface tensions, thin layers of the substance will improve lung compliance by reducing surface tension at liquid-gas interfaces, but will not prevent the alveoli from end-expiratory collapse. This holds true, particularly for small volumes of perfluorochemicals that might only fill a small number of dependent alveoli. If, in this scenario, the PEEP applied is not high enough to counterbalance the elevated retractive forces, the alveolar wall might be subjected to sheer 
forces that might promote alveolar rupture and successive pneumothorax formations [19]. Further studies are required to clarify the potential role of PLV in the development of pneumothoraces in experimental lung injury.

In conclusion, this study demonstrates that partial liquid ventilation with small volumes of FC 3280 is feasible and effective in improving short-term survival in experimental acute respiratory distress syndrome. However, total lung injury scores were not significantly different in both study groups and all animals were dead due to severe hypoxia, hypercapnia and pneumothoraces after $16 \mathrm{~h}$ of the experiment.

Recent concepts in the treatment of human acute respiratory distress syndrome primarily involve supportive measures aimed to maintain gas exchange, organ perfusion and aerobic metabolism while the acute lung injury resolves [20]. Partial liquid ventilation with even small volumes of perfluorocarbons might serve as a respiratory medium that helps to provide acceptable gas exchange until pulmonary function is re-established. However, subsequent animal studies on partial liquid ventilation are required to determine the interaction of perfluorocarbons with the endogeneous surfactant system [21], to ascertain nontoxicity and compatibility with other drugs used in the treatment of acute respiratory distress syndrome [22] and to evaluate methods of "weaning back" to gas ventilation once the underlying pulmonary disease process is improved.

\section{References}

1. Krafft P, Fridrich P, Pernerstorfer T, et al. The acute respiratory distress syndrome: definitions, severity and clinical outcome. An analysis of 101 clinical investigations. Intensive Care Med 1996; 22: 519-529.

2. Ashbaugh DG, Bigelow DB, Petty TL, Levine BE. Acute respiratory distress in adults. Lancet 1967; 11: 319323.

3. Fuhrman BP, Paczan PR, DeFrancisis M. Perfluorocarbon-associated gas exchange. Crit Care Med 1991; 19: 712-722.

4. Lowe Leach C, Fuhrman BP, Morin FC, Rath MR. Perfluorocarbon-associated gas exchange (PLV) in respiratory distress syndrome: a prospective, randomized, controlled study. Crit Care Med 1993; 21: 12701278.

5. Hirschl RB, Tooley R, Parent AC, Johnson K, Bartlett RH. Improvement of gas exchange, pulmonary function and lung injury with partial liquid ventilation. Chest 1995; 108: 500-508.

6. Tütüncü A, Houmes RJM, Bos JAH, Wollmer P, Lachmann B. Evaluation of lung function after intratracheal perfluorocarbon administration in healthy animals. Crit Care Med 1996; 24: 274-279.

7. Hirschl RB, Pranikoff T, Gauger P, Schreiner RJ, Dechert R, Bartlett RH. Liquid ventilation in adults, children and full-term neonates. Lancet 1995; 346: 1201-1202.

8. Lowe Leach C, Greespan JS, Rubenstein SD, et al. Partial liquid ventilation with perflubron in premature infants with severe respiratory distress syndrome. $N$ Engl J Med 1996; 335: 761-767.

9. Tütüncü AS, Faithfull NS, Lachmann B. Intratracheal perfluorocarbon administration combined with mechanical ventilation in experimental respiratory distress syndrome: dose-dependent improvement of gas exchange. Crit Care Med 1993; 21: 962-969.

10. Gauger PG, Pranikoff T, Schreiner RJ, Moler FW, Hirschl RB. Initial experience with partial liquid ventilation in pediatric patients with acute respiratory distress syndrome. Crit Care Med 1996; 24: 16-22.

11. Lachmann B, Robertson B, Vogel J. In vivo lung lavage as an experimental model of the respiratory distress syndrome. Acta Anaesthesiol Scand 1980; 24: 231-236.

12. Kaisers U, Max M, Schnabel R, et al. Partial liquid ventilation with FC 3280 in experimental respiratory distress syndrome: dose-dependent improvement of gas exchange and lung mechanics. Appl Cardiopulm Pathophysiol 1996; 6: 163-170.

13. Wegenius GA, Sjöstrand UH, Svensson BA, LichtwarckAschoff M, Markström AM, Nordgren AK. Radiological assessment of surfactant depletion lung injury. Appl Cardiopulm Pathophysiol 1996; 6: 119-129.

14. Lowe Leach C, Holm B, Morin FC, et al. Partial liquid ventilation in premature lambs with respiratory distress syndrome: efficacy and compatibility with exogenous surfactant. J Pediatrics 1995; 126: 412-420.

15. Tütüncü AS, Faithfull NS, Lachmann B. Comparison of ventilatory support with intratracheal perfluorocarbon administration and conventional mechanical ventilation in animals with acute respiratory failure. Am Rev Respir Dis 1993; 148: 785-792.

16. Overbeck MC, Pranikoff T, Yadao CM, Hirschl RB. Efficacy of perfluorocarbon partial liquid ventilation in a large animal model of acute respiratory failure. Crit Care Med 1996; 24: 1208-1214.

17. Hirschl RB, Pranikoff T, Wise C, et al. Initial experience with partial liquid ventilation in adult patients with the acute respiratory distress syndrome. JAMA 1996; 275: 383-389.

18. Lewis JF, Jobe AH. Surfactant and the adult respiratory distress syndrome. Am Rev Respir Dis 1993; 147: 218-233.

19. Pierson DJ. Alveolar rupture during mechanical ventilation: role of PEEP, peak airway pressure, and distending volume. Respir Care 1988; 33: 472-484.

20. Koleff MH, Schuster DP. The acute respiratory distress syndrome. N Engl J Med 1995; 323: 27-37.

21. Tütüncü AS, Houmes RJM, Bos JAH, Wollmer P, Lachmann B. Evaluation of lung function after intratracheal perfluorocarbon administration in healthy animals: pulmonary clearance of $99 \mathrm{mTc}-\mathrm{DTPA}$. Crit Care Med 1996; 24: 274-279.

22. Kaisers U, Rossaint R. Nitric oxide in partial liquid ventilation: better matching ventilation to perfusion in ARDS? Intensive Care Med 1997; 23: 139-140. 